\title{
Scintillation Properties of Yttrium-stabilized Zirconia Crystals Synthesized by the Floating-zone Method
}

\author{
Masaki Akatsuka, Daisuke Nakauchi, Noriaki Kawaguchi, and Takayuki Yanagida \\ Graduate School of Materials Science, Nara Institute of Science and Technology, \\ 8916-5 Takayama, Ikoma, Nara 630-0192, Japan
}

(Received November 30, 2018; accepted March 25, 2019)

Keywords: scintillation, $\mathrm{ZrO}_{2}$, single crystal, zirconia

We synthesized $\mathrm{ZrO}_{2}$ and yittria-stabilized $\mathrm{ZrO}_{2}$ crystals by the floating zone (FZ) method to evaluate their scintillation properties. Under excitation at around $250 \mathrm{~nm}$, the photoluminescence (PL) emission peak appeared at around $450 \mathrm{~nm}$. In the X-ray-induced scintillation spectra, an intense emission peak was also observed at around $450 \mathrm{~nm}$ in all the samples. The scintillation decay time profiles were approximated by a sum of two exponential decay functions, and the obtained value varied from 30-90 and 300-2230 ns depending on the composition.

\section{Introduction}

Scintillators are a kind of phosphor material, and they convert ionizing radiation (e.g., $\mathrm{X}$ - and $\beta$-rays) immediately to several thousands of low-energy photons such as ultraviolet and visible light. ${ }^{(1,2)}$ The application fields of scintillators are very wide, including medical imaging, ${ }^{(3)}$ security, ${ }^{(4)}$ oil logging, ${ }^{(5)}$ environmental monitoring, ${ }^{(6)}$ and high-energy physics. ${ }^{(7)}$ The basic requirements for a scintillator are a high light yield, a fast decay, a high density, a large effective atomic number, chemical stability, and radiation hardness. ${ }^{(2,8)}$ In reality, there is no perfect scintillator that fulfills all the properties required for all kinds of applications. Thus, we select suitable scintillators, such as those with the target radiation species, target energy, and target counting rate, depending on the purpose of each application.

$\mathrm{ZrO}_{2}$ is a wide-band-gap (5.0-5.5 eV) transition metal oxide with useful mechanical, thermal, optical, and electrical properties. ${ }^{(9,10)}$ Therefore, $\mathrm{ZrO}_{2}$ is used in various applications including semiconductor substrates, ${ }^{(1)}$ optical barrier coatings, ${ }^{(12,13)}$ high temperature solidoxide fuel cells and oxygen sensors, ${ }^{(14-16)}$ and the surface of nuclear fuel rods. ${ }^{(17,18)}$ The stable phases of $\mathrm{ZrO}_{2}$ are different between room and high temperatures, ${ }^{(19,20)}$ and this structural property causes a destruction of the bulk form of $\mathrm{ZrO}_{2}$ when it is exposed to a great change in temperature. In order to resolve the problem, additives such as yttrium, magnesium, and calcium oxide are used. These additives adjust the crystallographic structure by introducing oxygen vacancies and alter the electronic structure. Generally, this modification by additives (i.e.,

*Corresponding author: e-mail: akatsuka.masaki.ad5@ms.naist.jp https://doi.org/10.18494/SAM.2019.2189 
the introduction of vacancies and changes in crystallographic and electronic structures) leads to some useful carrier transport, chemical, and optical properties. ${ }^{(16,21-23)}$ From the viewpoint of optical applications, up to now, photoluminescence (PL) properties of $\mathrm{ZrO}_{2}$ and yttria-stabilized $\mathrm{ZrO}_{2}$ (YSZ or $\mathrm{Y}_{2} \mathrm{O}_{3}-\mathrm{ZrO}_{2}$ ) have been reported. ${ }^{(10,24,25)}$ Thus, $\mathrm{YSZ}$ is well known as one of the good phosphors. ${ }^{(26,27)}$ Furthermore, YSZ has a high density of $6 \mathrm{~g} / \mathrm{cm}^{3}$ so it has a high stopping power for radiation and absorbs radiation energy effectively. In some host materials, an inclusion of $\mathrm{Zr}$ enhances the detection probability of double beta decay $(0 v \beta \beta)$, which tests the validity of the grand unification theory, ${ }^{(28)}$ and $\mathrm{ZrO}_{2}$ may be applicable for such basic physics as well as industrial purposes.

Up to now, there have been reports on the radiation-induced luminescence properties of commercially available YSZ. ${ }^{(29)}$ However, as far as we know, no studies have been reported on the radiation-induced luminescence properties of YSZ with respect to $\mathrm{Y}$ concentration. In order to reveal the performance as a radiation detector, we synthesized $\mathrm{ZrO}_{2}$ and $\mathrm{YSZ}$ crystals by the floating zone (FZ) method and evaluated their scintillation and thermally stimulated luminescence (TSL) properties.

\section{Experimental Procedure}

The $\mathrm{ZrO}_{2}$ and YSZ ( $\mathrm{Zr:Y}=95: 5,92.5: 7.5,90: 10 \mathrm{~mol} \%$ ) samples used in this study were synthesized by the FZ method using four Xe lamps. ${ }^{(30)}$ The material powders were $\mathrm{ZrO}_{2}(4 \mathrm{~N})$ and $\mathrm{Y}_{2} \mathrm{O}_{3}(4 \mathrm{~N})$, and they were mixed to the above compositions. After mixing, the powders were formed into a cylindrical rod by applying hydrostatic pressure. Then, the cylinders of all the compositions were sintered at $1100{ }^{\circ} \mathrm{C}$ for $16 \mathrm{~h}$ in air to obtain ceramic rods. Finally, we conducted crystal growth by melting the ceramic rods via the FZ method in air. The FZ furnace used here was Crystal Systems FZ-T-12000-X-VPO-PC-YH, which has four xenon arc lamps $(3 \mathrm{~kW})$ and four ellipsoidal mirrors with a vertically positioned optical axis, enabling the axially symmetric heating of the zone. Owing to the use of such a high-power Xe lamp and isotropic irradiation, the inside temperature of the FZ furnace could rise to $3000{ }^{\circ} \mathrm{C}$. During crystal growth and the rotation rate was about $3 \mathrm{rpm}$ and the pull-down rate was about $15 \mathrm{~mm} / \mathrm{h}$.

The PL excitation and emission spectra were measured using a spectrofluorometer (FP8600, JASCO). The PL excitation/emission contour graph (or PL map) and PL quantum yield (QY) were measured using a Quantaurus-QY spectrometer (C11347, Hamamatsu Photonics). The excitation and emission wavelength ranges for the PL map were 250-450 and 300-700 nm, respectively. PL decay time profiles were evaluated using a Quantaurus- $\tau$ spectrometer (C11367, Hamamatsu Photonics), and the excitation and monitoring wavelengths were selected on the basis of the obtained PL contour map.

The scintillation spectra were evaluated at room temperature after X-ray irradiation using our original setup. ${ }^{(31)}$ The excitation source was an X-ray generator (XRB80N100, Spellman) equipped with a conventional X-ray tube, supplied with $80 \mathrm{kV}$ bias voltage and $1.2 \mathrm{~mA}$ tube current. The CCD (Newton 920, Andor) was cooled to $188 \mathrm{~K}$ by a Peltier device to reduce the thermal noise. In order to avoid the CCD being exposed to X-rays directly, the spectrometer was placed off the irradiation axis, and the scintillation light was guided into the spectrometer 
through a $2 \mathrm{~m}$ optical fiber. The scintillation decay time and afterglow profiles were measured using our original setup, the details of which can be found elsewhere. ${ }^{(32)}$ The voltage applied to the pulse X-ray source was $30 \mathrm{kV}$, and the system offers a timing resolution of $\sim 1 \mathrm{~ns}$. In order to characterize the relatively shallow trapping centers induced by X-ray irradiation, the TSL glow curves were measured using TL-2000 (Nanogray, Japan) with a heating rate of $1{ }^{\circ} \mathrm{C} / \mathrm{s}$ over the temperature range from 50 to $490{ }^{\circ} \mathrm{C} .{ }^{(33)}$ The typical duration between the irradiation of X-rays and TSL measurement was $\sim 1$ min.

\section{Results and Discussion}

As-synthesized rods were typically $4 \mathrm{~mm}$ in diameter and $15-20 \mathrm{~mm}$ in length. These rods were cut to pieces for characterization. Figure 1 shows the samples used for characterization. The $\mathrm{ZrO}_{2}$ sample appeared white, while YSZ samples were a transparent white. These colors are typical of $\mathrm{ZrO}_{2}$ and $\mathrm{YSZ}$ crystals. Because $\mathrm{ZrO}_{2}$ and $\mathrm{YSZ}$ were mechanically very hard, we could not polish the samples.

Figure 2 shows the PL (a) excitation and (b) emission spectra. The excitation spectra were different in $\mathrm{ZrO}_{2}$ and YSZ samples. The band-gap energy of YSZ is $5.0 \mathrm{eV}(250 \mathrm{~nm}),{ }^{(34)}$ and the excitation wavelength observed here was consistent. The emission spectrum of the $10 \%$-Y-doped sample was different from those of the 5 and $7.5 \%$-Y-doped samples. In a previous study, it was reported that YSZ had three main defect structures related to oxygen vacancies, and they affected the PL spectrum. ${ }^{(10)}$ On the basis of the previous results, we assign the emission at $450 \mathrm{~nm}$ observed in the samples except for the $10 \%$-Y-doped sample to a defect structure where all the nearest neighbors of $\mathrm{Zr}^{4+}$ are in oxygen vacancies with no neighboring $\mathrm{Y}^{3+}$ ions, and the emissions at 550 and $600 \mathrm{~nm}$ observed in the $10 \%$-Y-doped sample correspond to defect structures where a single oxygen vacancy has one and two neighboring $\mathrm{Y}^{3+}$ ions, respectively. ${ }^{(24,28)}$ Thus, we consider that the $10 \%$-Y-doped sample had an increased number of oxygen vacancies with neighboring $\mathrm{Y}^{3+}$ ions since the number of $\mathrm{Y}$ ions is larger than those

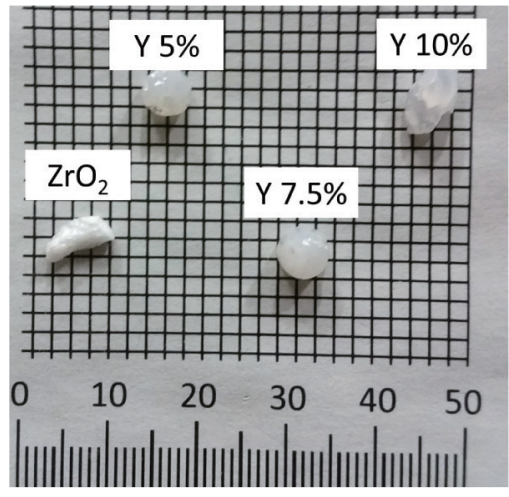

Fig. 1. Photograph of $\mathrm{ZrO}_{2}$ and $\mathrm{YSZ}$.

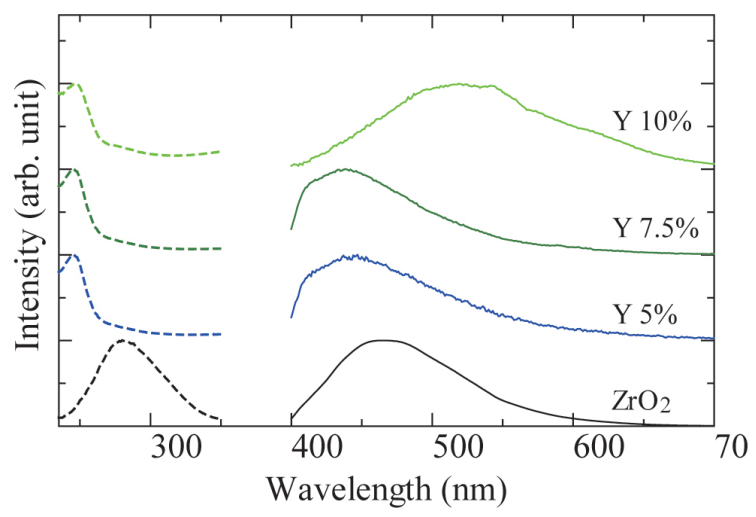

Fig. 2. (Color online) PL (a) excitation and (b) emission spectra of samples with different $\mathrm{Y}$ concentrations. 
in the other samples, and the emission peak shifted to a longer wavelength. The excitation and emission spectra of $\mathrm{ZrO}_{2}$ were consistent with those in a previous study of ceramic $\mathrm{ZrO}_{2}$. ${ }^{(35)}$

The PL emission map and PL decay curve of only the $\mathrm{ZrO}_{2}$ sample were able to be evaluated owing to the high emissivity, and we indicate them in Figs. 3 and 4, respectively. The PL map is consistent with the PL spectra, and the QY was 19.1\% with the integration of photons from 400 to $650 \mathrm{~nm}$. The PL decay time profile of $\mathrm{ZrO}_{2}$ monitored at $450 \mathrm{~nm}$ under $280 \mathrm{~nm}$ excitation is represented in Fig. 4. The obtained decay time constants are 4.6 and $25.7 \mu \mathrm{s}$. We think that the fast component $(4.6 \mu \mathrm{s})$ is caused by some kind of defect of $\mathrm{ZrO}_{2}$ because similar results were reported previously in powder $\mathrm{ZrO}_{2}{ }^{(36)}$ Moreover, we consider that the slow component is also due to some kind of defect of $\mathrm{ZrO}_{2}$. Because $\mathrm{ZrO}_{2}$ undergoes a phase transition upon a large temperature change, $\mathrm{ZrO}_{2}$ is considered to have various types of defect structures during the cooling process of crystal growth.

Figure 5 shows X-ray-induced scintillation spectra. The $\mathrm{ZrO}_{2}$ and $\mathrm{YSZ}$ samples showed broad emission bands at around 450 and $500 \mathrm{~nm}$, respectively. Only Nakauchi et al. reported the scintillation properties of YSZ, ${ }^{(29)}$ and furthermore, no reports can be found about the scintillation properties of $\mathrm{ZrO}_{2}$. Here, we interpret the origins of scintillation emission taking into account the PL properties. The emission features of YSZ samples were similar to those

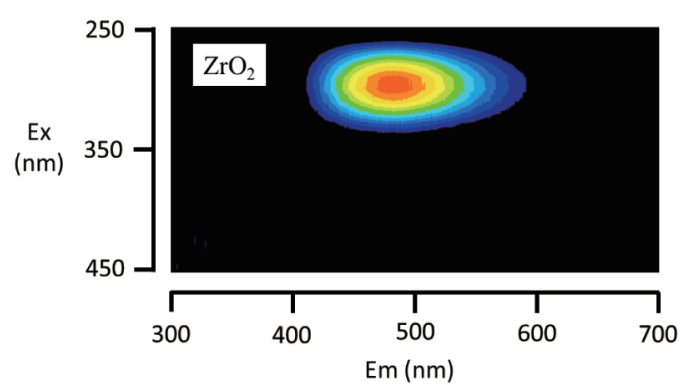

Fig. 3. (Color online) PL emission map of $\mathrm{ZrO}_{2}$. The horizontal and vertical axes show emission and excitation wavelengths, respectively.

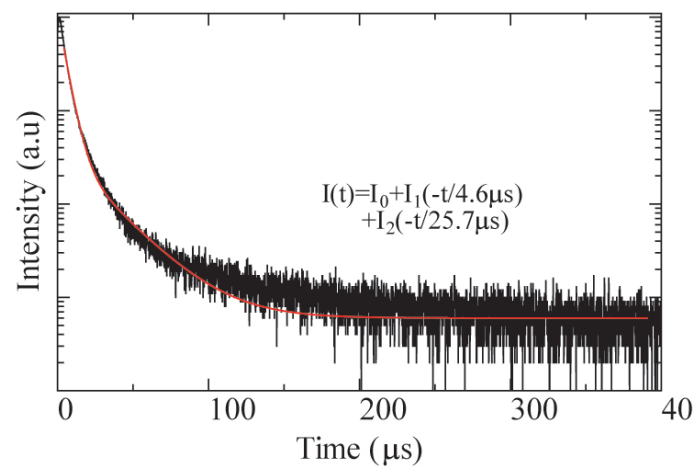

Fig. 4. (Color online) PL decay curve of $\mathrm{ZrO}_{2}$ sample. The monitoring wavelength was around 450 $\mathrm{nm}$.

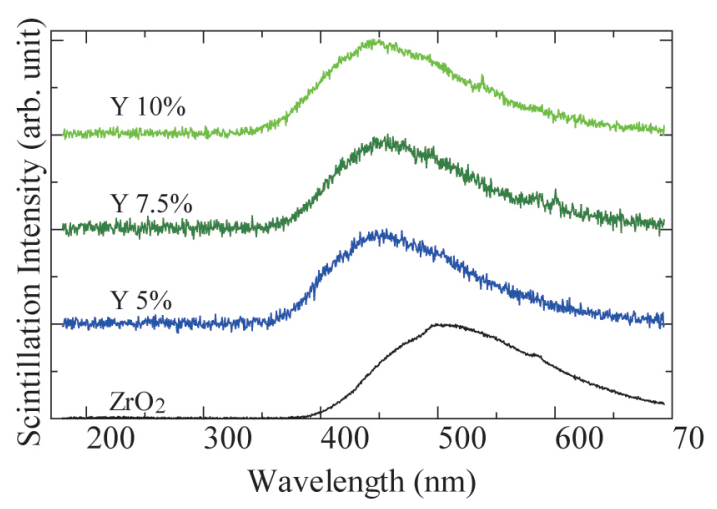

Fig. 5. (Color online) X-ray-induced scintillation spectra of $\mathrm{ZrO}_{2}$ doped with different concentrations of Y. 
in the past study and can be identified as being due to the defect centers surrounded by $\mathrm{Zr}^{4+}$ ions. ${ }^{(29)}$ We considered that the emission of the $\mathrm{ZrO}_{2}$ sample was also due to the defect centers surrounded by $\mathrm{Zr}^{4+}$ ions since the spectral shape was similar to that of PL. This result indicates that scintillation properties of YSZ were changed by the stabilization of the crystal structure. The broad feature of the emission spectrum may suggest that there are some other overlapping emission bands with different origins.

Figure 6 shows X-ray-induced scintillation decay time profiles of $\mathrm{ZrO}_{2}$ and $\mathrm{YSZ}$ samples. The decay curves of all samples were approximated as a sum of two exponential functions. The fast component is ascribed to the oxygen vacancy. On the other hand, the origin of the slow component is unclear, but the values of the two components are dramatically different in YSZ and $\mathrm{ZrO}_{2}$ samples, suggesting different emission origins. In the case of YSZ, in a previous study, the emission due to self-trapped excitons (STEs) was pointed out, ${ }^{(29)}$ and STE may be one of the possible origins of the slow component. Moreover, the scintillation decay times of $\mathrm{ZrO}_{2}$ were faster than those of PL. In general, the scintillation decay time is slower than that of PL. A possible reason is some kind of quenching among secondary electrons generated by X-ray irradiation. Similar behaviors were observed in different phosphors, as reported elsewhere. ${ }^{(37)}$

The X-ray-induced afterglow profiles of all samples are shown in Fig. 7. Here, the irradiation time was $2 \mathrm{~ms}$ assuming a scanning X-ray imaging setup, where a line detector with a width of $1 \mathrm{~mm}$ takes an X-ray image of an object traveling at a speed of $50 \mathrm{~cm} / \mathrm{s}$ on a line belt. In this evaluation, afterglow level $(A)$ is represented as $A(\%)=100 \times\left(I_{2}-I_{0}\right) /\left(I_{1}-I_{0}\right)$, where $I_{0}, I_{1}$, and $I_{2}$ denote the averaged signal intensity before the X-ray irradiation, the averaged signal intensity during X-ray irradiation, and the signal intensity at $t=20 \mathrm{~ms}$ after terminating the X-ray irradiation, respectively. The afterglow levels of the 0 -, 5.0-, 7.5-, and 10\%-Y-doped samples are $0.79,0.04,0.06$, and $0.04 \%$, respectively. The value of the $\mathrm{ZrO}_{2}$ sample is much larger than that of $\mathrm{SrAl}_{2} \mathrm{O}_{4}$, which is a famous material with a storage luminescence. ${ }^{(38)}$ Such a high afterglow level suggests that there are a large number of shallow traps; thus, most of the carriers generated by X-ray irradiation are temporarily captured.

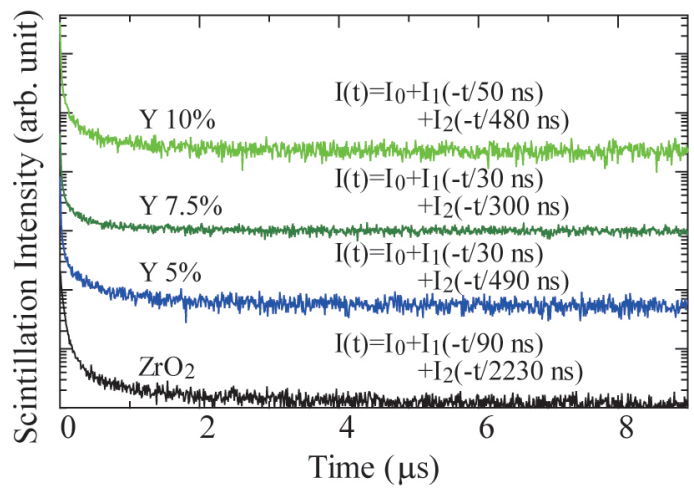

Fig. 6. (Color online) X-ray-induced scintillation decay time profiles of $\mathrm{ZrO}_{2}$ doped with different concentrations of $\mathrm{Y}$.

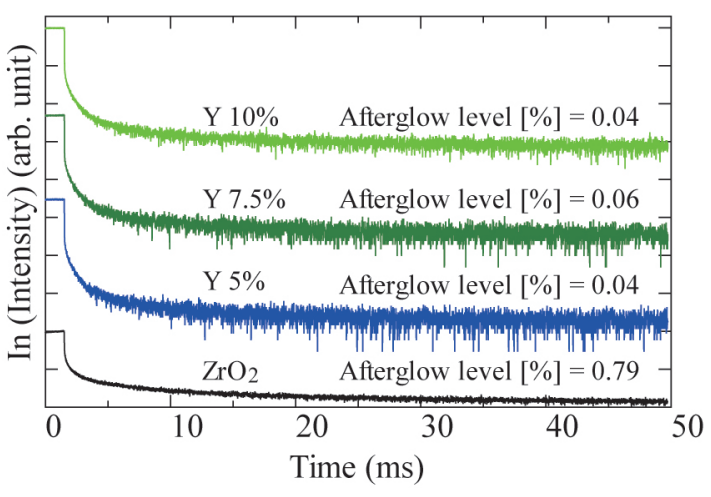

Fig. 7. (Color online) Afterglow profiles of $\mathrm{ZrO}_{2}$ doped with different concentrations of $\mathrm{Y}$ after the $\mathrm{X}$-ray irradiation was terminated. 


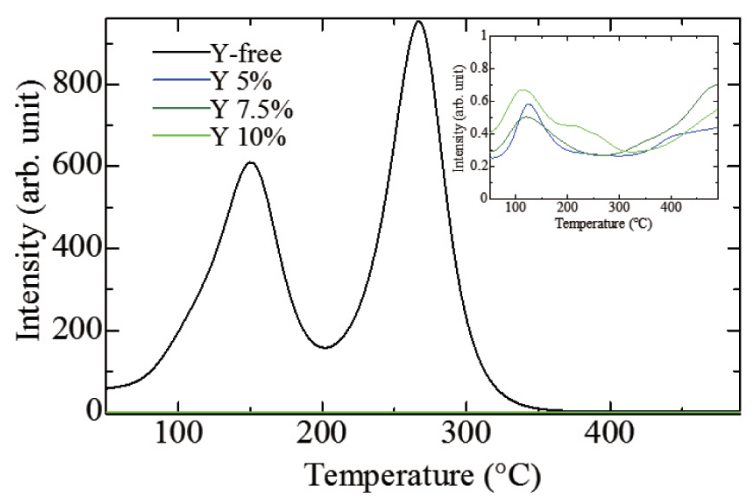

Fig. 8. (Color online) TSL glow curves of $\mathrm{ZrO}_{2}$ doped with different concentrations of $\mathrm{Y}$ after 1 Gy X-ray irradiation. The monitored wavelength was $250-550 \mathrm{~nm}$. The inset has a magnified vertical line.

Figure 8 shows TSL glow curves of $\mathrm{ZrO}_{2}$ doped with different concentrations of $\mathrm{Y}$. The glow curves were measured after the $1 \mathrm{~Gy} \mathrm{X}$-ray irradiation. The $\mathrm{ZrO}_{2}$ sample demonstrated two strong peaks at around 150 and $260{ }^{\circ} \mathrm{C}$. The glow peak at $150{ }^{\circ} \mathrm{C}$ was consistent with the results of other experiments conducted with $\mathrm{ZrO}_{2}$ after X-ray irradiation. ${ }^{(39)}$ However, the other glow peak at $260{ }^{\circ} \mathrm{C}$ had not been reported. The origin of this peak may be some defect generated in the high-temperature synthesis, since in most of the studies so far, synthesis used temperatures lower than those in the present work. YSZ samples showed glow peaks detected at $100{ }^{\circ} \mathrm{C}$ and over $490{ }^{\circ} \mathrm{C}$. Moreover, only the $10 \%$-Y-doped sample showed a glow peak at around $210^{\circ} \mathrm{C}$. A similar glow peak was reported in the previous study of YSZ. ${ }^{(29)}$ Thus, the introduced $\mathrm{Y}$ may be the origin of the $\sim 210{ }^{\circ} \mathrm{C}$ peak. In addition, all the samples had a peak at $50{ }^{\circ} \mathrm{C}$. This finding means that all the samples have shallow trapping centers that are re-excited at room temperature; this is the root of the high afterglow level represented in Fig. 7.

\section{Conclusions}

We synthesized $\mathrm{ZrO}_{2}$ and YSZ by the FZ method to evaluate their PL, scintillation, and TSL properties. In scintillation, all the samples demonstrated a broad peak at around 450 or 500 $\mathrm{nm}$. The scintillation decay curves of YSZ could be approximated by a sum of two exponential decay functions. The decay time was in the ranges of 30-50 and 300-490 ns. These decay times were faster than those in $\mathrm{ZrO}_{2} . \mathrm{ZrO}_{2}$ showed intense TSL glow peaks at 150 and $260{ }^{\circ} \mathrm{C}$. On the other hand, Y-stabilized $\mathrm{ZrO}_{2}$ showed emission peaks at around $110{ }^{\circ} \mathrm{C}$ and over $490{ }^{\circ} \mathrm{C}$.

\section{Acknowledgments}

This work was supported by Grants-in-Aid for Scientific Research (A) (17H01375) and (B) (18H03468) from the Ministry of Education, Culture, Sports, Science and Technology of the Japanese government (MEXT) as well as A-STEP from Japan Science and Technology Agency (JST). The Cooperative Research Project of the Research Institute of Electronics, Shizuoka 
University, Terumo Foundation for Life Sciences and Arts, Izumi Science and Technology Foundation, The Kazuchika Okura Memorial Foundation, and The Iwatani Naoji Foundation are also acknowledged.

\section{References}

1 T. Yanagida: Proc. Jpn. Acad. B 94 (2018) 75.

2 C. W. E. Eijk: Nucl. Instrum. Methods Phys. Res., Sect. A 460 (2001) 1.

3 S. Yamamoto, K. Kuroda, and M. Senda: IEEE Trans. Nucl. Sci. 50 (2003) 1683.

4 J. Glodo, Y. Wang, R. Shawgo, C. Brecher, R. H. Hawrami, J. Tower, and K. S. Shah: Phys. Procedia 90 (2017) 285.

5 T. Yanagida, Y. Fujimoto, S. Kurosawa, K. Kamada, H. Takahashi, Y. Fukazawa, M. Nikl, and V. Chani: Jpn. J. Appl. Phys. 52 (2013) 076401.

6 K. Watanabe, T. Yanagida, K. Fukuda, A. Koike, T. Aoki, and A. Uritani: Sens. Mater. 27 (2015) 269.

7 T. Ito, T. Yanagida, M. Sato, M. Kokubun, T. Takashima, S. Hirakuri, R. Miyawaki, H. Takahashi, K. Makishima, T. Tanaka, K. Nakazawa, T. Takahashi, and T. Honda: Nucl. Instrum. Methods Phys. Res., Sect. A 579 (2007) 239.

8 S. E. Derenzo, M. J. Weber, E. Bourret-Courchesne, and M. K. Klintenberg: Nucl. Instrum. Methods Phys. Res., Sect. A 505 (2003) 111.

9 J. D. Fidelus, S. Yatsunenko, M. Godlewski, W. Paszkowicz, E. W. Malentob, and W. Łojkowski: Scr. Mater. 61 (2009) 415.

10 N. G. Petrik, D. P. Taylor, and T. M. Orlando: J. Appl. Phys. 85 (1999) 6770.

11 V. A. Loebs and T. W. Haas: J. Vac. Sci. Technol. A 1 (1983) 596.

12 D. P. Taylor, W. C. Simpson, K. Knutsen, M. A. Henderson, and T. M. Orlando: Appl. Surf. Sci. 127-129 (1998) 101.

13 N. Mansour, K. Mansour, E. W. V. Stryland, and M. J. Soileau: J. Appl. Phys. 67 (1989) 1475.

14 S. Jiang, W. A. Shulze, and G. C. Stange: J. Mater. Chem. 12 (1997) 2374.

15 G. Lu, N. Miura, and N. Yamazoe: J. Mater. Chem. 7 (1997) 1445.

16 C. Leo'n, M. L. Lucia, and J. Santamar1: Phys. Rev. B 55 (1997) 882.

17 B. Cox: J. Nucl. Mater. 148 (1987) 332.

18 C. Lemaignan: J. Nucl. Mater. 187 (1992) 122.

19 P. Li, I.-W. Chen, and J. E. Penner-Hahn: Phys. Rev. B 48 (1993) 10074.

20 E. V. Stefanovich, A. L. Shluger, and C. R. A. Catlow: Phys. Rev. B 49 (1994) 11560.

21 M. Croset, J. P. Schnell, G. Velasco, and J. Siejka: J. Appl. Phys. 48 (1977) 775.

22 W. Yeh, C. Patuwathavithane, and R. H. Zee: J. Appl. Phys. 79 (1996) 7809.

23 B. Alexandrov, A. Y. Bychkov, A. I. Vall, N. G. Petrik, and V. M. Sedov: J. Phys. Chem. 65 (1991) 1604.

24 S. E. Paje and J. L. lopis: J. Phys. D 29 (1996) 442.

25 B. Savoini, J. E. Muñoz Santiuste, and R. González: Phys. Rev. 56 (1997) 5856.

26 Y. Scen and D. R. Clarke: J. Am. Ceram. Soc. 92 (2009) 125

27 S. Heiroth, R. Ghisleni, T. Lippert, J. Michler, and A. Wokaun: Acta Mater. 59 (2011) 2330

28 Y. Fukuda, S. Moriyama, and I. Ogawa: Nucl. Instrum. Methods Phys. Res., Sect. A 732 (2013) 397.

29 D. Nakauchi, G. Okada, and T. Yanagida: J. Lumin. 172 (2016) 61.

30 D. Nakauchi, G. Okada, N. Kawaguchi, and T. Yanagida: Jpn. J. Appl. Phys. 57 (2018) 100307.

31 T. Yanagida, K. Kamada, Y. Fujimoto, H. Yagi, and T. Yanagitani: Opt. Mater. 35 (2013) 2480.

32 T. Yanagida, Y. Fujimoto, T. Ito, K. Uchiyama, and K. Mori: Appl. Phys. Exp. 7 (2014) 062401.

33 T. Yanagida, Y. Fujimoto, N. Kawaguchi, and S. Yanagida: J. Ceram. Soc. Jpn. 121 (2013) 989.

34 V. R. PaiVerneker, A. N. Petelin, F. J. Crowne, and D. C. Nagle: Phys. Rev. 40 (1989) 8555.

35 S. Nakayama and M. Sakamoto: J. Mater. Res. Technol. 5 (2016) 289.

36 C. Lin, C. Zhang, and J. Lin: J. Phys. Chem. C 111 (2007) 3300.

37 T. Yanagida and G. Okada: J. Ceram. Soc. Jpn. 124 (2016) 564.

38 D. Nakauchi, G. Okada, M. Koshimizu, and T. Yanagida: J. Lumin. 176 (2016) 342.

39 P. Salas, E. De la Rosa-Cruz, D. Mendoza-Anaya, P. González, R. Rodriguez, and V. M. Castano: Mater. Lett. 45 (2000) 241. 